\title{
Effects of Drought Stress During Critical Periods on Photosynthesis Characteristics and Production Performance of Naked Oat (Avena Nuda. L)
}

\author{
Xinjun Zhang \\ Zhangjiakou Academy of Agricultural Sciences \\ Wenting Liu \\ Zhangjiakou Academy of Agricultural Sciences \\ Yaci Lv \\ Hengshui University \\ Tianliang Li \\ Zhangjiakou Academy of Agricultural Sciences \\ Jianzhao Tang \\ Hebei Academy of Sciences \\ Xiaohong Yang \\ Zhangjiakou Academy of Agricultural Sciences \\ Jing Bai \\ Zhangjiakou Academy of Agricultural Sciences \\ Xin Jin \\ Beijing Normal University \\ Haitao Zhou ( $\nabla$ zht0206@163.com ) \\ Zhangjiakou Academy of Agricultural Sciences
}

\section{Research Article}

Keywords: naked oat, drought stress, photosynthetic characteristics, chlorophyll fluorescence, yield, yield components

Posted Date: December 10th, 2021

DOI: https://doi.org/10.21203/rs.3.rs-1135270/v1

License: (c) (i) This work is licensed under a Creative Commons Attribution 4.0 International License. Read Full License 


\section{Abstract}

Revealing the effects of drought stress during the critical period on the photosynthetic characteristics and production performance of naked oats could provide theoretical basis for optimizing the water managements and selecting the drought resistance cultivars. In this study, a potted experiment consisting of four water levels was conducted, to investigate the response of photosynthesis, chlorophyll fluorescence, biomass, yield and yield components of to drought stress during 12-15 days before heading at a typical site in Zhangjiakou. Results showed that the initial chlorophyll fluorescence rate $\left(F_{0}\right)$ increased by $9.03-50.92 \%$ under drought stress, while the maximum fluorescence rate $\left(F_{\mathrm{m}}\right)$ and photochemical efficiency (Fv/Fm) decreased by $8.49-19.73 \%$ and $10.37-24.12 \%$. Moreover drought stress decreased the photosynthetic rate $\left(P_{\mathrm{n}}\right)$, transpiration rate $\left(T_{\mathrm{r}}\right)$, stomatal conductance $\left(G_{\mathrm{s}}\right)$. The $\mathrm{CO}_{2}$ concentration $\left(C_{\mathrm{i}}\right)$ decreased under light drought stress, while increased under moderate and severe drought stress. Drought stress during critical periods also had significant impacts on oat yield and yield components. Oat yields decreased by $9.5-12.7 \%$, 16.8-27.0\% and 44.1-47.7\% under light, moderate and sever drought stress, respectively. The yield components such as grains per spike, 1000-grain weight were decreased by $1.7-12.5 \%, 8.3-24.3 \%, 32.7-34.2 \%$ and $5.7-8.6 \%, 12.7-14.5 \%, 16.8-19.1 \%$ under light, moderate and severe drought stress, respectively. But the Spike numbers were not signifigantly different between different treatments. Our study explored the impacts of drought stress on the photosynthetic characteristics and production performance of naked oats, which had significance for enhancing the production efficiency for oat under drought stress.

\section{Introduction}

Naked oat ( $A$. nuda $\mathrm{L}$ ) is a traditional food, feed and forage crop in North China (Ren and Hu, 2013). Due to its rich nutrients content, it is significance for keeping the human health (Ren and $\mathrm{Hu}, 2013$ ). However, oat is a water-costing crop, and the water requirement of which during growing period is more than wheat and barley (Xiao and Yang, 1992). Drought stress has significant impacts on oat production, especially during critical growing periods, i.g. 12-15 days before heading (Ren and Hu, 2013). Research shows that water stress at different stages (tillering, jointing and flowering stages) can reduce the grain weight per plant, number of effective ears, number of spikelets and 1000 grains weight, which result in grain shrinkage, and then affect the yield of oats. So drought stress at each stage can reduce the photosynthetic products transported from oats to grains (Wang, 2019). Water shortage decreases the photosynthetic rate, stomatal conductance and intercellular $\mathrm{CO}_{2}$ content (Bai et al., 2006).

Photosynthesis is the basis for dry matter accumulation and yield formation (Zhongwu Li et al.,). However, drought stress mainly damages the physiological metabolism and photosynthesis of plants (Xu, 2002; Bai et al., 2006), which reduce crop production (Zheng et al., 2006; Nielsen et al., 2009). Leaf is the main photosynthetic organ, and its photosynthetic capacity was mainly influenced by water condition (Boyer,

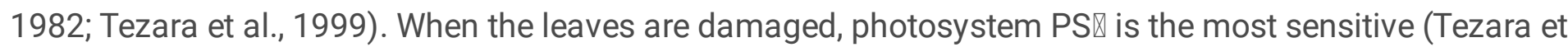
al., 1999). Under water stress, the light use efficiency and photosynthetic capacity of oat leaves decreased

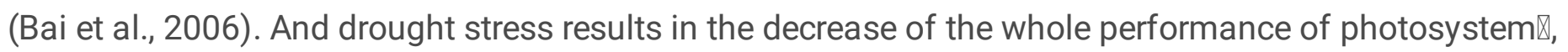
which leads to the decrease of dry matter accumulation (Gao et al., 2015). 
Bashang area of Hebei Province is one of the staple naked oats production areas in China. However, water shortage, characterized by low and highly variable amounts of precipitation, is the major limiting factor for oat production in this region (Chavers et al., 2009; Li et al., 2021). Some studies were conducted to evaluate the impacts of drought stress on oat production in this region. Ge (2010) studied the photosynthetic mechanism of different water use efficiency (WUE) in Bashang area, results showed that with the extension of drought stress time and the aggravation of drought stress degree, the main limiting factors for the decrease of photosynthetic rate were change from stomatal factors to non stomatal factors, and different germplasm had different responses to water stress.

However, the evaluation based on the structure and function of light system was rarely in this region. Therefore, the objectives of this study were to: 1 ) reveal the response of structure and function of light system of naked oats to different drought stress levels; 2) understand the energy balance of oat leaves under drought stress; 3 ) explore the change rule of photosynthetic electron transfer and gas exchange parameters under different drought stress.

\section{Materials And Methods}

\subsection{Study site, climate and soil data}

The experiment was conducted at Xishungou station ( $\left.41^{\circ} 3^{\prime} 54^{\prime \prime} \mathrm{N}, 114^{\circ} 4^{\prime} 18^{\prime \prime} \mathrm{E}\right)$ of Zhangjiakou Academy of Agricultural Sciences from 2018 to 2019 . The station is characterized by a typical continental climate with abundant solar radiation, warm summers and cold winters. The annual total solar radiation, average temperature and precipitation were $5400-6120 \mathrm{MJ} / \mathrm{m}^{2}, 3.7^{\circ} \mathrm{Cand} 400 \mathrm{~mm}$ respectively. The soil type is chestnut soil and the detailed soil information is shown in Table 1

Table 1

Vertical distribution of the physical and chemical properties of soil in the study site.

\begin{tabular}{|c|c|c|c|c|c|c|}
\hline Year & $\begin{array}{l}\text { Soil depth } \\
\text { (cm) }\end{array}$ & $\begin{array}{l}\text { Available } \mathrm{N} \\
(\mathrm{mg} / \mathrm{kg})\end{array}$ & $\begin{array}{l}\text { Available P } \\
(\mathrm{mg} / \mathrm{kg})\end{array}$ & $\begin{array}{l}\text { Available K } \\
(\mathrm{mg} / \mathrm{kg})\end{array}$ & $\begin{array}{l}\text { Organic carbon } \\
(\mathrm{g} / \mathrm{kg})\end{array}$ & $\mathrm{pH}$ value \\
\hline \multirow[t]{2}{*}{2018} & $0-20$ & 50.92 & 29.97 & 55.21 & 10.23 & 6.96 \\
\hline & $20-40$ & 53.97 & 19.39 & 42.40 & 9.24 & 6.95 \\
\hline \multirow[t]{2}{*}{2019} & $0-20$ & 48.68 & 20.66 & 39.38 & 10.15 & 7.12 \\
\hline & $20-40$ & 52.75 & 17.93 & 46.92 & 12.00 & 7.10 \\
\hline
\end{tabular}

\subsection{Experimental design}

To explore the impacts of drought stress on the on photosynthesis characteristics and production performance of Naked oat, potted experiments were conducted for two years from 2018 to 2019, with four water levels each year. The cultivar of Huazao2 was planted, which bred by Zhangjiakou Academy of Agricultural Sciences. The plastic buckets with same specifications (inner diameter $28.5 \mathrm{~cm}$, depth $33.5 \mathrm{~cm}$ ) were used to plant the materials and every bucket load $23.15 \mathrm{~kg}$ of air dried chestnut soil (the basin weight is 
$0.85 \mathrm{~kg}$ ). The maximum soil water holding capacity was tested by the cutting ring method and soil nutrient parameters are (to be tested). A plastic filter screen is arranged at the bottom of the barrel to separate the bottom and the upper part of the barrel from a certain space, and a hard plastic pipe beside the bucket leading to the bottom of the barrel is used for watering. Four treatments were set in the experiment: normal water supply (CK), light drought stress (LS), moderate drought stress (MS) and severe drought stress (SS), the soil relative water content were $70-80 \%, 60-70 \%, 50-60 \%$ and $35-45 \%$ of the maximum soil water capacity respectively. There were 6 repetitions in total, 20 seedlings per basin were fixed in three leaf stage, water control was started at about 20 days before booting stage, and natural drought to the standard range of soil moisture content. At 8:00 and 18:00 every day, water was replenished and controlled by weighing method and recorded, which lasted for 7 days after reaching the expected 4 different levels of drought stress, and photosynthetic rate and chlorophyll fluorescence were measured for 3 consecutive days. After that, all treatments were restored to normal watering level. Except for the obvious difference of soil moisture in the bucket, the other management was all the same. Each index was measured with the third leaf of each repeated sample. After maturing and harvesting, the economic and yield characters of naked oats were measured in the laboratory.

\subsection{Measurements}

\subsubsection{Photosynthetic rate}

The photosynthetic rate of naked oats leaves were measured at 09:00-11:00 am in sunny day by LC pro ${ }^{+}$ portable full-automatic photosynthetic measurement system produced by ADC company in UK under natural condition. Each treatment repeated 6 times. Three healthy functional leaves on naked oats were selected for the measurement. Three data were measured each time. The average value was taken as the measured value at that time. The parameters obtained were net photosynthetic rate (Pn), stomatal conductance (Gs), intercellular $\mathrm{CO}_{2}$ concentration (Ci) and transpiration rate (Tr).

\subsubsection{Chlorophyll fluorescence:}

The chlorophyll fluorescence value of naked oats was determined by the Fluerpen FP100 chlorophyll fluorescence meter produced in Czech Republic. The parameters obtained are the initial fluorescence value Fo, the maximum fluorescence value (Fm), and the light energy conversion efficiency Fv/Fm of the PS区 center.

\subsubsection{The yield and yield components of oat}

After harvested in mature stage, 10 plants taken from each pot were tested, and plant height, ear length, spikelet number, ear grain weight, stem number, ear number, ear grain number, 1000 grain weight are measured in the Lab. After seed test, grain yield and biomass are measured, and the remaining 10 plants in the basin are combined to calculate the total 20 plants grain yield and biomass in each pot.

\subsection{Statement}

All experimental research and field studies on plants in this article comply with relevant institutional, national, and international guidelines and legislation. 


\section{Results}

\subsection{Effects of drought stress on photosynthetic characteristics}

The photosynthetic rate under LS, MS and SS were significantly lower than the CK $(P<0.05)$, and the values decreased by $9.30 \%, 14.08 \%$ and $20.89 \%$ respectively in 2018 , for 2019 the decrease amounts were $14.43 \%$, $16.85 \%$ and $24.55 \%$ (Fig. $1 \mathrm{a}$ and b). With the increase of drought stress, the Ci decreased first and then increased (Fig. 1C and d). Compared with CK, the Ci decreased by $12.41 \%$ under LS, while it increased by 9.49\% under SS, and the difference was not significantly under MS in 2018 (Fig. 1C). In 2019, the Ci under LS was significantly increased. The Ci under MS and SS was $4.94 \%$ and $13.09 \%$ higher than that of CK $(P<0.05)$, respectively (Fig. 1d). With the increase of drought stress, the Tr gradually decreased (Fig. 1e and f). The Tr under LS, MS and SS in two years was significantly lower than CK $(P<0.05)$, and the $\operatorname{Tr}$ decreased by $10.83 \%$, $41.39 \%$ and $45.61 \%$ in 2018 (Fig. 1e), for 2019 the values were $21.85 \%, 29.30 \%$ and $45.77 \%$ (Fig. 1f). With the aggravation of drought stress, Gs of naked oats showed a decreasing trend (Fig. $1 \mathrm{~g}$ and h). In 2018, the difference of Gs under LS and CK was not significance, while in MS and SS the Gs decreased by $35.68 \%$ and $78.89 \%$, respectively compared with CK (Fig. 1g). In 2019, the Gs under LS, MS and SS were $26.04 \%, 46.88 \%$ and $85.42 \%$ lower than CK $(P<0.05)$ (Fig. $1 \mathrm{~h})$.

\subsection{Effects of drought stress on photosystem $₫$}

The initial fluorescence value (Fo) increased with the aggravation of drought stress (Fig. 2a and b). In 2018, the Fo under LS, MS and SS were $9.03 \%, 9.89 \%$ and $14.13 \%$ higher than CK $(P<0.05)$ (Fig. 2a). While, in 2019, the Fo was only increased significantly under MS and SS values were $24.84 \%$ and $50.92 \%$ higher than CK $(P<0.05)$ (Fig. 2b). Maximum fluorescence value $(\mathrm{Fm})$ decreased with the increase of drought stress (Fig. 2c and $\mathrm{d})$. The difference of $\mathrm{F}_{\mathrm{m}}$ under LS and CK was not significant $(P>0.05)$ in 2018, while the Fm under MS and SS were $8.49 \%$ and $19.73 \%$ lower than that CK $(P<0.05)$ (Fig. 2C). In 2019, the Fm under LS, MS and SS were $10.02 \%, 15.83 \%$ and $21.89 \%$ lower than CK $(P<0.05)$ (Fig. 2d). Variable fluorescence of PS $\llbracket$ decreased significantly under drought stress (Fig. 2e and f), the Fv values under LS, MS and SS were $19.05 \%, 37.62 \%$ and $92.86 \%$ lower than CK in $2018(P<0.05)$, and the values were $43.68 \%, 49.43 \%$ and $72.41 \%$ in 2019 (Fig. 2e and f). Drought stress decreased the activity of PS『significantly (Fig. $2 \mathrm{~g}$ and h), the Fv/Fo values under LS, MS and SS were 16.24\%, 25.41\% and 46.82\% lower than CK in $2018(P<0.05)$, and the values were $27.24 \%, 47.44 \%$ and $66.99 \%$ in 2019 (Fig. $2 \mathrm{~g}$ and $\mathrm{h}$ ). Fv/Fm values under drought stress were lower than CK (Fig. $2 \mathrm{i}$ and j). There was no significant difference between LS and CK $(P>0.05)$, while the values under MS and SS were significantly CK $(P<0.05)$, which decreased by $10.37 \%$ and $24.12 \%$ (Fig. $2 \mathrm{i})$. In 2019 , Fv/Fm under LS, MS and SS decreased by $13.3 \%, 22.44 \%$ and $36.83 \%$, respectively (Fig. $2 \mathrm{j}$ ).

\subsection{Effects of drought stress on main economic characters}

With the aggravation of drought stress, the plant height of naked oats decreased gradually (Table 1). There was no significant difference between LS and CK for plant height in two years, while the height decreased by $6.30 \%$ and $8.01 \%$ in 2018 under MS and SS $(P<0.05)$, for 2019 the height decreased by $7.88 \%$ and $22.16 \%$ 
$(P<0.05)$ (Table 1). Drought stress decreased ear length significantly (Table 1$)$. Under LS, the ear length decreased slightly for the two years, under MS and SS, the length decreased by $16.37 \%$ and $12.52 \%$ in 2018 $(P<0.05)$, and decreased by $17.29 \%$ and $12.28 \%$ in $2019(P<0.05)$ (Table 1$)$. The spikelet number under LS and MS were not significantly different from $\mathrm{CK}$, while the number decreased by 12.6 and $21.9 \%$ under SS $(P<0.05)$ in 2018 and 2019 (Table 1). The grain weight per ear under LS, MS and SS were $21.86 \%, 31.25 \%$ and $34.38 \%$ lower $(P<0.05)$ than CK in 2018, while in 2019 the grain weight per ear under LS was not significantly from CK, under MS and SS, the grain weight per ear decreased by 21.88 and $53.13 \%$ (Table 1 ). Drought stress reduced the tillering ability (Table 1). There was no significance difference between the stem number under LS and CK in two years $(P>0.05)$, while under MS and SS the stem number decreased by 11.24 and $15.73 \%, 16.17$ and $33.03 \%$ in 2018 and 2019 (Table 1).

Table 1

Effects of drought stress on economic characteristics of naked oats

\begin{tabular}{|c|c|c|c|c|c|c|}
\hline Year & Treatment & $\begin{array}{l}\text { Plant } \\
\text { height }\end{array}$ & Ear length & $\begin{array}{l}\text { Spikelet } \\
\text { number }\end{array}$ & $\begin{array}{l}\text { Grain weight per } \\
\text { ear }\end{array}$ & $\begin{array}{l}\text { Stem } \\
\text { number }\end{array}$ \\
\hline \multirow[t]{4}{*}{2018} & CK & $64.0 \pm 2.6 \mathrm{a}$ & $13.9 \pm 0.5 \mathrm{a}$ & $30.9 \pm 0.3 \mathrm{a}$ & $3.2 \pm 0.1 \mathrm{a}$ & $44.5 \pm 1.7 \mathrm{a}$ \\
\hline & LS & $\begin{array}{l}62.5 \pm 2.3 \\
a b\end{array}$ & $14.7 \pm 0.2 \mathrm{a}$ & $28.7 \pm 2.1 \mathrm{a}$ & $2.5 \pm 0.2 b$ & $42.5 \pm 0.9 a b$ \\
\hline & MS & $59.0 \pm 1.2 b$ & $11.6 \pm 0.4 b$ & $28.5 \pm 1.4 \mathrm{a}$ & $2.2 \pm 0.2 \mathrm{bc}$ & $39.5 \pm 2.3 \mathrm{bc}$ \\
\hline & SS & $49.8 \pm 3.4 \mathrm{c}$ & $12.1 \pm 1.0 \mathrm{~b}$ & $24.2 \pm 1.4 \mathrm{~b}$ & $2.1 \pm 0.1 \mathrm{c}$ & $37.5 \pm 1.5 c$ \\
\hline \multirow[t]{4}{*}{2019} & CK & $64.7 \pm 5.0 \mathrm{a}$ & $\begin{array}{l}13.3 \pm 0.6 \\
a b\end{array}$ & $32.6 \pm 1.3 \mathrm{a}$ & $3.3 \pm 0.1 \mathrm{a}$ & $43.3 \pm 5.0 \mathrm{a}$ \\
\hline & LS & $\begin{array}{l}58.7 \pm 2.3 \\
a b\end{array}$ & $13.7 \pm 1.5 \mathrm{a}$ & $31.3 \pm 3.1 \mathrm{ab}$ & $3.1 \pm 0.3 \mathrm{a}$ & $39.3 \pm 2.5 \mathrm{ab}$ \\
\hline & MS & $53.3 \pm 2.9 \mathrm{~b}$ & $11.0 \pm 1.0 \mathrm{c}$ & $28.9 \pm 0.9 \mathrm{ab}$ & $2.5 \pm 0.1 \mathrm{~b}$ & $36.3 \pm 2.9 \mathrm{~b}$ \\
\hline & SS & $54.7 \pm 5.0 \mathrm{~b}$ & $\begin{array}{l}11.7 \pm 0.6 \\
\text { bc }\end{array}$ & $28.5 \pm 2.4 \mathrm{~b}$ & $1.5 \pm 0.3 \mathrm{c}$ & $29.0 \pm 1.0 \mathrm{c}$ \\
\hline
\end{tabular}

\subsection{Effects of drought stress on yield components}

The difference was not significantly for spike number among the drought stress treatments in 2018, for 2019 , only SS significantly decreased the spike number and which was $28.7 \%$ lower than CK (Table 2). The performance of grain number per spike was different in the two years, and the grain number per spike decreased by $12.55 \%, 24.32 \%$ and $34.21 \%$, respectively in 2018 under LS, MS and SS, while in 2019 the grain number per spike only decreased significantly under SS $(P<0.05)$, with the value of $34.4 \%$ (Table 2$)$. The 1000 -grain weight decreased significantly under MS and SS, and which decreased by $14.5 \%$ and $16.8 \%$ in 2018, and the values in 2019 were $12.2 \%$ and $18.4 \%$ (Table 2). Drought stress decreased biomass significantly in $2018(P<0.05)$, and the biomass decreased by $6.39 \%, 18.3 \%$ and $21.3 \%$ under LS, MS and SS, respectively (Table 2). In 2019, the decrease amount of biomass was not significantly under LS, and the biomass decreased by $14.75 \%$ and $17.69 \%$ under MS and SS (Table 2). The change trend of yield was similar with the biomass, the yield decreased by $12.7 \%, 26.9 \%$ and $44.1 \%$ under LS, MS and SS in 2018 
(Table 2). In 2019, the decrease of yield was not significantly under LS, while the yield decreased by $16.85 \%$ and $47.76 \%$ under MS and SS (Table 2). Drought stress also decreased the harvest index significantly in both years (Table 2).

Table 2

Effects of drought stress on yield component, yield and biomass of naked oats

\begin{tabular}{|c|c|c|c|c|c|c|c|}
\hline Year & Treatment & $\begin{array}{l}\text { Spike } \\
\text { number }\end{array}$ & $\begin{array}{l}\text { Grains per } \\
\text { spike }\end{array}$ & $\begin{array}{l}1000- \\
\text { grain } \\
\text { weight }\end{array}$ & Yield & Biomass & $\begin{array}{l}\text { Harvest } \\
\text { index }\end{array}$ \\
\hline \multirow[t]{4}{*}{2018} & CK & $\begin{array}{l}26.0 \pm 2.6 \\
a\end{array}$ & $\begin{array}{l}148.7 \pm 6.2 \\
a\end{array}$ & $\begin{array}{l}22.0 \pm 1.0 \\
a\end{array}$ & $\begin{array}{l}113.39 \pm 4.97 \\
a\end{array}$ & $\begin{array}{l}323.50 \pm 3.40 \\
\text { a }\end{array}$ & $\begin{array}{l}0.35 \pm 0.02 \\
a\end{array}$ \\
\hline & LS & $\begin{array}{l}27.3 \pm 1.2 \\
\text { a }\end{array}$ & $\begin{array}{l}130.1 \pm 12.7 \\
b\end{array}$ & $\begin{array}{l}20.1 \pm 1.1 \\
a b\end{array}$ & $\begin{array}{l}99.04 \pm 3.96 \\
\mathrm{~b}\end{array}$ & $\begin{array}{l}302.83 \pm 8.34 \\
\text { b }\end{array}$ & $\begin{array}{l}0.33 \pm 0.01 \\
a b\end{array}$ \\
\hline & MS & $\begin{array}{l}29.3 \pm 1.5 \\
\text { a }\end{array}$ & $\begin{array}{l}112.6 \pm 5.3 \\
\mathrm{C}\end{array}$ & $\begin{array}{l}18.8 \pm 0.7 \\
b\end{array}$ & $\begin{array}{l}82.80 \pm 5.87 \\
\mathrm{c}\end{array}$ & $\begin{array}{l}264.23 \pm 5.49 \\
\mathrm{C}\end{array}$ & $\begin{array}{l}0.31 \pm 0.03 \\
b\end{array}$ \\
\hline & SS & $\begin{array}{l}26.7 \pm 2.1 \\
\mathrm{a}\end{array}$ & $97.9 \pm 2.7 d$ & $\begin{array}{l}18.3 \pm 1.3 \\
b\end{array}$ & $\begin{array}{l}63.34 \pm 2.29 \\
d\end{array}$ & $\begin{array}{l}254.58 \pm 15.40 \\
\mathrm{C}\end{array}$ & $\begin{array}{l}0.25 \pm 0.01 \\
c\end{array}$ \\
\hline \multirow[t]{4}{*}{2019} & CK & $\begin{array}{l}38.3 \pm 5.7 \\
\text { a }\end{array}$ & $\begin{array}{l}141.3 \pm 10.0 \\
a\end{array}$ & $\begin{array}{l}22.8 \pm 0.5 \\
a\end{array}$ & $110.0 \pm 7.4 \mathrm{a}$ & $\begin{array}{l}327.2 \pm 22.01 \\
a\end{array}$ & $\begin{array}{l}0.34 \pm 0.00 \\
a\end{array}$ \\
\hline & LS & $\begin{array}{l}35.7 \pm 3.1 \\
\text { a }\end{array}$ & $\begin{array}{l}138.7 \pm 9.9 \\
a\end{array}$ & $\begin{array}{l}21.5 \pm 1.5 \\
a b\end{array}$ & $\begin{array}{l}99.5 \pm 13.12 \\
a b\end{array}$ & $\begin{array}{l}306.3 \pm 19.97 \\
a b\end{array}$ & $\begin{array}{l}0.32 \pm 0.04 \\
a\end{array}$ \\
\hline & MS & $\begin{array}{l}32.7 \pm 3.1 \\
a b\end{array}$ & $\begin{array}{l}129.0 \pm 6.1 \\
a\end{array}$ & $\begin{array}{l}20.0 \pm 1.9 \\
\text { bc }\end{array}$ & $91.5 \pm 9.85 b$ & $\begin{array}{l}278.9 \pm 14.89 \\
b\end{array}$ & $\begin{array}{l}0.33 \pm 0.05 \\
a\end{array}$ \\
\hline & SS & $27.3 \pm 3.1$ & $92.7 \pm 6.1 \mathrm{~b}$ & $\begin{array}{l}18.6 \pm 1.9 \\
c\end{array}$ & $57.5 \pm 5.22 \mathrm{c}$ & $\begin{array}{l}269.3 \pm 34.87 \\
b\end{array}$ & $\begin{array}{l}0.21 \pm 0.02 \\
b\end{array}$ \\
\hline
\end{tabular}

\section{Discussions}

\subsection{The response of photosynthetic efficiency to drought stress}

The decrease of photosynthetic rate under drought stress is a common phenomenon (Ren et al., 2020). Under drought stress, the net photosynthetic rate $(\mathrm{Pn})$ decreased sharply with the increase of drought stress. Based on the change trends of $\mathrm{Pn}, \mathrm{Gs}$ and $\mathrm{C}_{\mathrm{i}}$, the restriction of stomatal factors or not can be judged (Farquhar and Sharkey, 1982). In the early stage of drought stress (or light drought stress), stomata closed first to reduce water transpiration, thus preventing $\mathrm{CO}_{2}$ from entering the leaves (Bai et al., 2006; Liu et al., 2015). Our results showed that the Pn, Gs and $\mathrm{Ci}$ under mild drought stress were lower, which indicated that stomatal restriction was the main factor. The main reason might be that drought stress caused water loss of plant cells to occur osmotic stress, and stomatal closure hindered the expansion of external $\mathrm{CO}_{2}$ gas into cells (Zhang et al., 2013; Wu et al., 2017). The decrease of photosynthetic substrate inhibited the increase of photosynthetic rate. However, under moderate and severe drought stress, with the decrease of Pn and Gs, the 
concentration of $\mathrm{Ci}$ gradually increased, indicating that with the deepening of drought stress, non-stomatal restriction gradually became the main factor of the decrease of photosynthetic rate, which may be due to the damage of chloroplast structure (Zhang et al, 2013).

\subsection{The impacts of drought stress on photosystem \}

Chlorophyll fluorescence can reflect the primary photosynthetic reaction process including the absorption of light energy, the transmission of excitation energy and photochemical reaction (Zhang et al., 2004). The degree of damage caused by stress can be reflected by measuring chlorophyll fluorescence parameters, the light utilization in PS®(Miyashita et al., 2005). Under drought stress, plants maintain the balance of water budget by reducing the transpiration rate, which is an adaptive way to avoid drought (Schreiber et al., 1994). The Fo reflects the damage degree of thylakoid membrane, more serious the damage of thylakoid membrane induced the higher Fo (Schreiber and Bilger, 1993). The maximum fluorescence reflects the electron transfer through PS囚. Lower Fm reflects the higher the degree of thermal damage (Schreiber and

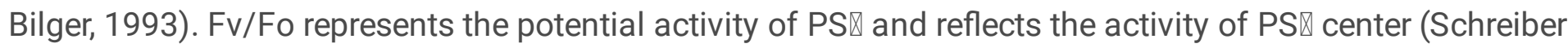
and Bilger, 1993; Wu et al., 2019). The Fv/Fm of plants is generally $0.75-0.85$ under non stress conditions (Csintalan et al., 1999; He et al., 2005), and it will be significantly reduced under adversity or injury conditions (Xu et al., 1992). Our results of two years showed that Fo in oat leaves increased with the increase of water stress during the critical period, which indicated that the damage degree of thylakoid in leaves increased gradually with the deepening of water stress. Fm decreased under water stress, which indicated that the electrical transmission of leaves through PS $\triangle$ was inhibited and the degree of heat damage was deepened. $\mathrm{Fv} / \mathrm{Fo}$ and $\mathrm{Fv} / \mathrm{Fm}$ in oat leaves were lower than those under $\mathrm{CK}$, which indicated that water stress reduced the efficiency of capturing light energy in $P S \otimes$ reaction center of leaves.

\subsection{Effect of drought stress on economic and yield characters of naked oats}

In the critical period of water requirement, the plant height, ear length, ear grain weight, stem number and 1000 grain weight of naked oats all decreased gradually under different drought stress. Research shows that drought stress would decrease wheat yield and composition factors (Zhang et al., 2011; Ren et al., 2020). In addition, the development of organs is affected significantly under long-term stress (Liu et al., 2020). Previous studies showed that drought stress can inhibit the growth of oat ear, leaf, stem and root (Zhang et al., 2013; Liu et al., 2015; Wu et al., 2017). Although the accumulation and distribution of dry matter were not determined in this study, the variation of biomass with drought stress was similar to the above studies. Mild drought had little effect on oat biomass, while moderate and severe drought had greater effect on oat biomass. Compared with light stress, oat yield and yield components decreased more under moderate and sever drought stress, the reason would be that the photosynthesis capacity of the leave decrease more under the moderate and sever drought stress.

\subsection{The limitation of the study}

Due to the limited conditions, the experiment only controlled the soil water content, and set the degree of soil drought stress based on it, but did not measure the actual stress degree of oat plants. In addition, only photosynthesis, fluorescence and laboratory test were carried out in the experiment, and the changes of 
physiological indexes related to drought stress of oat were not measured. The next step is to determine the stress degree of oat according to the leaf water potential, and to determine the drought stress related indicators such as superoxide dismutase (SOD) and peroxidase (POD) activities, malondialdehyde (MDA) content etc.

\section{Conclusions}

In the critical period of water requirement, drought stress reduced the photosynthetic efficiency of oat. Under light drought stress, stomatal restriction was the main factor that led to the decrease of photosynthetic rate of naked oat. Under moderate and severe drought stress, the thylakoid of naked oat leaves was damaged, the electron transfer through PS $\otimes$ was inhibited, and non-stomatal restriction gradually became the main factor that led to the decrease of photosynthetic rate. The decrease of photosynthetic rate resulted in the inhibition of economic characters, yield components, seed yield and biomass of naked oats. In 2018 , the yield of light drought stress, moderate drought stress and severe drought stress decreased by $12.7 \%, 26.9 \%$ and $44.1 \%$ respectively, and in 2019 , the yield of moderate and severe drought stress decreased by $16.85 \%$ and $47.76 \%$ respectively.

\section{References}

1. Bai, L. P., Sui, F. G., Ge, T. D., Sun, Z. J., Lu, Y. Y., \& Zhou, G. S. (2006). Effect of soil drought stress on leaf water status, membrane premeability and enzymatic antioxidant system of maize. Pedosphere, 2006, 326-332.

2. Bai, X. L., Qi, H., He, P., Yu, G. R., Zhang, Y. L., Li, C., Jin, L. L., \& Ren, Z. P. (2006). Effects of water stress on the photosynthetic characteristics of the leaf of oats during its grain-filling stage. Rain Fed Crops, 26(1), 25-27. (in Chinese)

3. Boyer, J. S. (1982). Plant productivity and environment. Science, 218, 443-448.

4. Chavers, M. M., Flexas, J., \& Pinheiro, C. (2009). Photosynthetics under drought and salt stress: Regulation mechanisms from whole plant to cell. Annals of botany, 103, 551-560

5. Csintalan, Z., Proctor, M. C. F., \& Tuba, Z. (1999). Chlorophyll fluorescence during drying and rehydration in the mosses Rhytidiadelphus loreus (Hedw.) Warnst., Anomodon viticulosus (Hedw.) Hook. \& Tayl. and Grimmia pulvinata (Hedw.) Sm. Annals of Botany, 84, 235-244区

6. Farquhar, G. D., \& Sharkey, T. D. (1982). Stomatal conductance and photosynthesis. Annual Review of Plant Physiology, 33(3), 317-345.

7. Gao, J., Zhang, R. H., Wang, W. B., Li, Z. W., \& Xue, J. Q. (2015). Effects of drought stress on performance of photosystem $\otimes$ in maize seeding stage. Chinese Journal of Applied Ecology, 26(5), 1391-1396. (in Chinese)

8. Ge, J. Y. (2014). The screening on nakes oat (Avena nuda) germplasm with high water use efficiency and study on mechanism of water and nitrogen use efficiency. China Agricultural University. (in Chinese) 


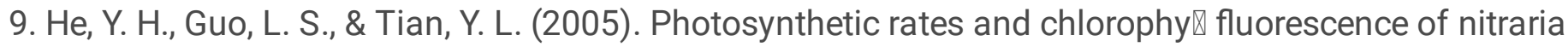
tangutorum at different leaf water potentials. Acta Botanica Boreall-Occideali Sinica, 25(11), 2226-2233. (in Chinese)

10. Li, Y. X., Zhou, H. T., \& Liu, W. T. (2021). Photosynthetic fluorescence characteristics and drought resistance evaluation of different oat varieties under drought stress. Seed, 40 (2), 26-34. (in Chinese)

11. Liu, J. X., Wang, J. C., Wang, R. J., \& Jia, H. Y. (2015). Effects of nitric oxide on growth and physiological characteristics of oat seedings under drought stress. Chinese Journal of Grassland, 37(2), 41-45. (in Chinese)

12. Liu, K. Q., Liu, W. H., Jia, Z. F., Ma, X., \& Liang, G. L. (2020). Effects of water stress on organ growth and water use efficiency of Avena sativa 'Qingyan No. 1'. Acta Agrestia Sinica, 28(6), 1552-1556. (in Chinese)

13. Miyashita, K., Tanakamaru, S., Maitani, T., \& Kimura, K. (2005). Recovery responses of photosynthesis, transpiration, and stomatal conductance in kidney bean following drought stress. Environmental and Experimental Botany, 53, 205-214

14. Nielsen, D. C., Vigil, M. F., \& Benjamin, J. G. (2009). The variable response of dry land corn yield to soil water content at planting. Agricultural Water Management, 96, 330-336.

15. Ren, C. Z., \& Hu, Y. G. (2013). Chinese Oatology. Beijing, China Agriculture Press. (in Chinese)

16. Ren, J., Sun, M., \& Ren, A. X. (2020). Difference in water consumption and yield among different droughtresistant wheat cultivars. Chinese Journal of Eco-Agriculture, 28(2), 211-220. (in Chinese)

17. Ren, J., Sun, M., Lin, W., Xue, J. F., Tong, J., Wang, W. X., \& Gao, Z. Q. (2020). Difference in water consumption and yield among different drought-resistant wheat cultivars. Chinese Journal of EcoAgriculture, 28(2), 211-220. (in Chinese)

18. Schreiber, U., Bilger, W., \& Neubauer, C. (1994). Chlorophyll fluorescence as a non-destructive indicator for rapid assessment of in vivo photosynthesis. Ecological Studies, 100, 49-70.

19. Tezara, W., Mitchell, V. J., Dirscoll, S. D., \& Lawlor, D. W. (1999). Water stress inhibits plant photosynthesis by decreasing coupling factor and ATP. Nature, 401, 914-917.

20. Wang, X. X. (2019). Effects of water stress and rewatering on yield and physiological characteristics of oats in different periods. Northeast Normal University. (in Chinese)

21. Wu, J. Y., Lian, W. J., Liu, Z. G., Zhang, X. Y., Jiang, J. F., \& Wei, Y. N. (2019). High temperature response of chlorophy $\otimes$ fluorescence parameters and heat tolerance evaluation of different grape cultivars. Journal of Northwest A \& F University, 47(6), 80-88.

22. Wu, X. H., \& Feng, J. M. (2017). Effect of extraneous spermidine on growht and some physiological characteristics in oat seeding under PEG stress. Journal of Triticeae Crops, 37(1), 122-129. (in Chinese)

23. Xiao, D. H., \& Yang, H. P. (1992). General situation of collection and identification of oat genetic resources in China. Crops, 3, 6-9. (in Chinese)

24. Xu, D. Q. (2002). Photosynthetic Efficiency. Shanghai, Shanghai Science and Technology Press. (in Chinese) 
25. Xu, D. Q., Zhang, Y. Z., \& Zhang, R. X. (1992). Photoinhinition of photosynthesis in plants. Plant Physiology Communications, 28(4), 237-243. (in Chinese)

26. Zhang, J. Z., Shi, L., \& Shi, A. P. (2004). Photosynthetic responses of four Hosta cultivars to shade treatment. Photosynthetica, 42(2), 213-218区

27. Zhang, N., Zhao, B. P., Zhang, Y. L., Ren, P., Liu, J. H., \& Wang, Y. (2013). Comparative experiment on drought-resistan characteristics of different oat cultivars. Agricultural Research in the Arid Areas, 31(1), 166-171. (in Chinese)

28. Zhang, Y. Q., Liu, Q., Liu, J. B., Zhang, H. S., \& Zhao, C. X. (2011). Effects of drought stress on photosynthetic characteristics and yield of different fertilizer and water types of wheat. Journal of Triticeae Crops, 31(4), 724-730. (in Chinese)

29. Zheng, S. H., \& Yan, C. R. (2006). The eco-physiological and morphological characteristics of maize in seeding stage under water stress. Acta Ecologica Sinica, 26(4), 1138-1143『in Chinese区

\section{Figures}
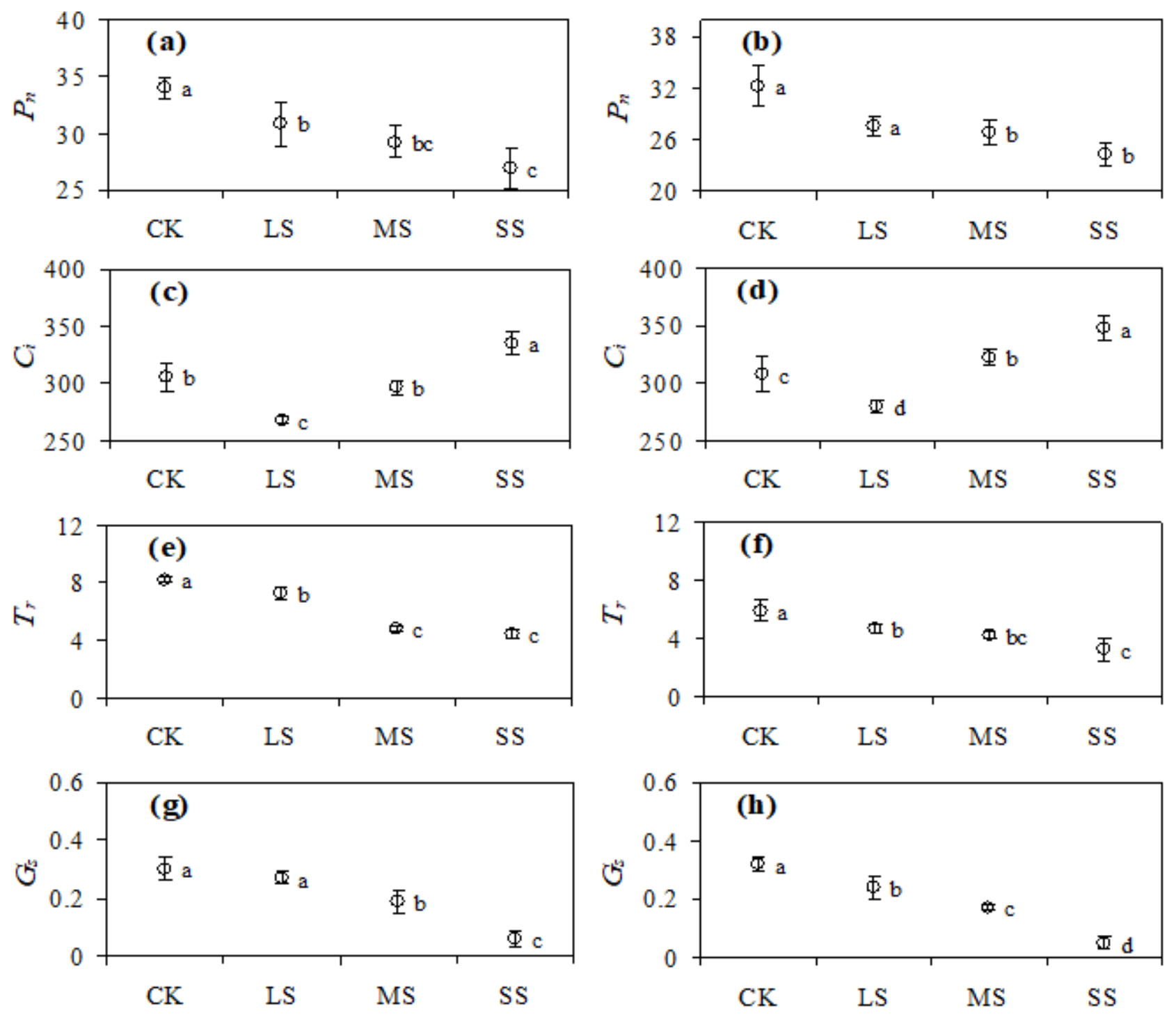
Figure 1

The photosynthetic rate $(\mathrm{Pn}, \mu \mathrm{mol} \cdot \mathrm{m}-2 \cdot \mathrm{s}-1)$, intercellar $\mathrm{CO} 2$ concentration $(\mathrm{Ci}, \mu \mathrm{mol} \cdot \mathrm{mol}-2)$, transpiration rate

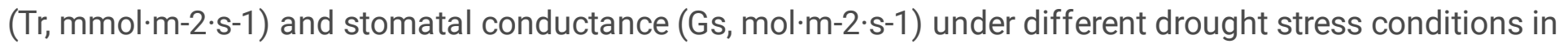
2018 and 2019. a, c, e and $g$ represents the values in 2018, b, d, $f$ and $h$ represent the values in 2019. The same letters above the error bars indicate no significant difference at $\mathrm{P}=0.05$.
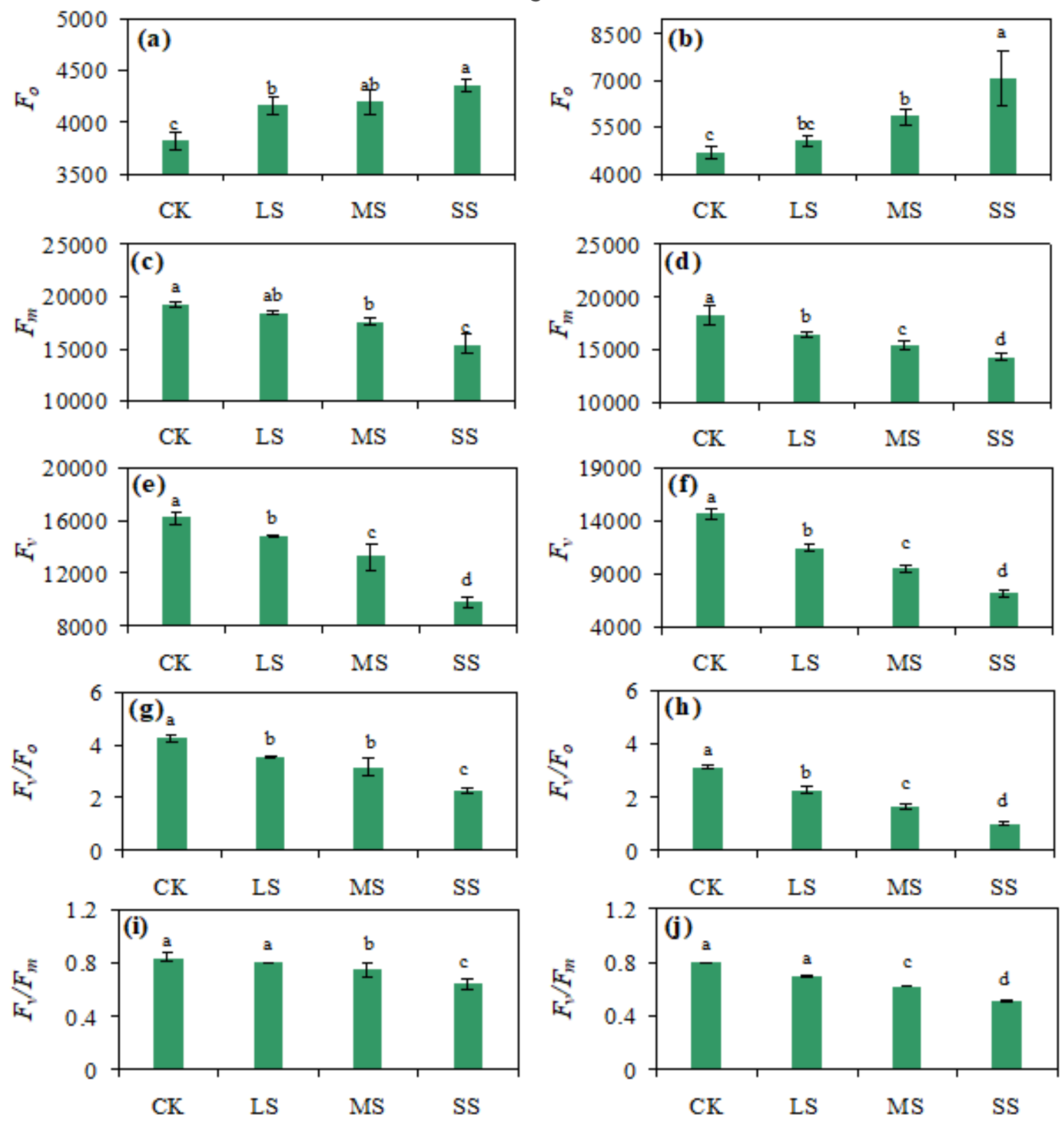

\section{Figure 2}

The initial fluorescence value (Fo), Maximum fluorescence value (Fm), Fv/Fo and Fv/Fm under different drought stress conditions in 2018 and 2019. a, c, e and g represents the values in 2018, b, d, f and $h$ represent the values in 2019. The same letters above the error bars indicate no significant difference at $\mathrm{P}=0.05$. 